\title{
Life history variation in cupuladriid bryozoans from either side of the Isthmus of Panama
}

\author{
Aaron O'Dea ${ }^{1,2, *}$, Amalia Herrera-Cubilla ${ }^{1}$, Helena Fortunato ${ }^{1}$, Jeremy B. C. Jackson ${ }^{1,2}$ \\ ${ }^{1}$ Center for Tropical Paleoecology and Archeology, Smithsonian Tropical Research Institute, Box 2072, Balboa, Ancon, \\ Republic of Panama \\ ${ }^{2}$ Geosciences Research Division, Scripps Institution of Oceanography University of California, San Diego La Jolla, \\ California 92093-0244, USA
}

\begin{abstract}
Cupuladriid bryozoans are able to produce new colonies both sexually through the production of larvae and asexually via fragmentation. The prevalence of asexual propagation and the physical and biological processes of fragmentation in cupuladriid species are currently little understood. In a large survey comprising collections of nearly 32000 cupuladriids from either side of the Isthmus of Panama, patterns of cupuladriid species richness, occurrence and abundance were measured together with levels of asexual propagation, fragmentation and regeneration. The Caribbean side is characterised by greater cupuladriid diversity and dominance of the genus Cupuladria over Discoporella while the eastern Pacific coast is characterised by lower cupuladriid diversity and complete dominance of Discoporella. Life history variation was not found to be constrained by phylogeny and no systematic differences were found in life history or morphologies between Cupuladria and Discoporella to explain the patterns in generic dominance across the isthmus. Nonetheless, striking differences occur in life history strategies across the isthmus. Eastern Pacific species tend to be large, flat and lightly calcified, resulting in high levels of fragmentation and hence asexual propagation. Conversely, Caribbean species produce a wider range of morphologies, including small, highly domed and highly calcified colonies that protect from fragmentation. By correlating colony morphologies with reproductive life histories within species, we show that morphologies, particularly colony strength and size, control levels of fragmentation and thus mode of propagation in cupuladriids. Life history strategies that promote asexual propagation are found to track levels of primary productivity both between oceans across the isthmus and between regions within oceans.
\end{abstract}

KEY WORDS: Asexual $\cdot$ Sexual $\cdot$ Life history $\cdot$ Cupuladriid $\cdot$ Bryozoa $\cdot$ Reproduction $\cdot$ Panama

\section{INTRODUCTION}

Compared to solitary organisms, colonial organisms have a greater potential for increasing the number of individuals in a population through breakage or separation (Jackson et al. 1985). Such processes of asexual propagation occur across a wide variety of both animal and plant species that adopt a colonial habit (e.g. Jackson 1979, 1986, Harper 1977, Highsmith 1982, McKinney 1983, Hughes \& Cancino 1985, Jackson \& Hughes 1985, Jackson et al. 1985, Jackson \& Coates 1986, Wulff 1991, Smith \& Hughes 1999, Boller et al. 2002) and can take place by means of a number of processes including fission, partial mortality and fragmentation (Jackson 1985). The biological, ecological and evolutionary implications of asexual propagation are immediately apparent. For example, an organism can bypass the often costly or hazardous processes of sexual reproduction (Lewis 1987), and in so doing may become dominant within an area and theoretically become immortal. A population with high rates of asexual reproduction is likely to have significantly less genetic variability than one in which sexual reproduction readily occurs (e.g. Hoffman 1986), and a population with dominant asexuality may become genetically homogenous in both space and time (Hughes \& Jackson 1980, Håkansson \& Thomsen 2001). 


\section{Sexual and asexual propagation in cupuladriid bryozoans}

The 2 cupuladriid genera, Cupuladria and Discoporella, are pan-tropical and subtropical marine Bryozoa in the order Cheilostomida (e.g. Fig. 1). Like most cheilostome bryozoans, they are both clonal and colonial, their colonies being composed of budded modules termed zooids (McKinney \& Jackson 1989). Unlike most cheilostomes, however, cupuladriid colonies are not fixed to the substrate but are instead motile, able to rest free from the bottom, move over the sediment surface and upwards through sediment following burial. The distinctive morphology of small discoidal or domed colonies required for such a 'freeliving' life habit (Fig. 1) have evolved independently in at least 4 unrelated groups of bryozoans: the Cupuladriidae Lagaaij, 1952, the Mamilloporidae Canu \& Bassler, 1927, the Otionellidae Bock \& Cook, 1998, and the 2 closely related families Lunulitidae Lagaaij, 1952 and Selenariidae Busk, 1854 that are part of the superfamily Microporoidea (e.g. Håkansson 1973, Cook \& Chimonides 1978, 1994, Cheetham \& Jackson 2000).

It is well documented that cupuladriid bryozoans can establish new colonies either sexually, through the formation of a lecithotrophic larva, or asexually, via the splitting of colonies and the subsequent regenerative growth of the resulting fragments (Fig. 2) (e.g. Dartevelle 1932, Marcus \& Marcus 1962, Lagaiij 1963, Cook 1965, Baluk \& Radwanski 1977, Håkansson \& Winston

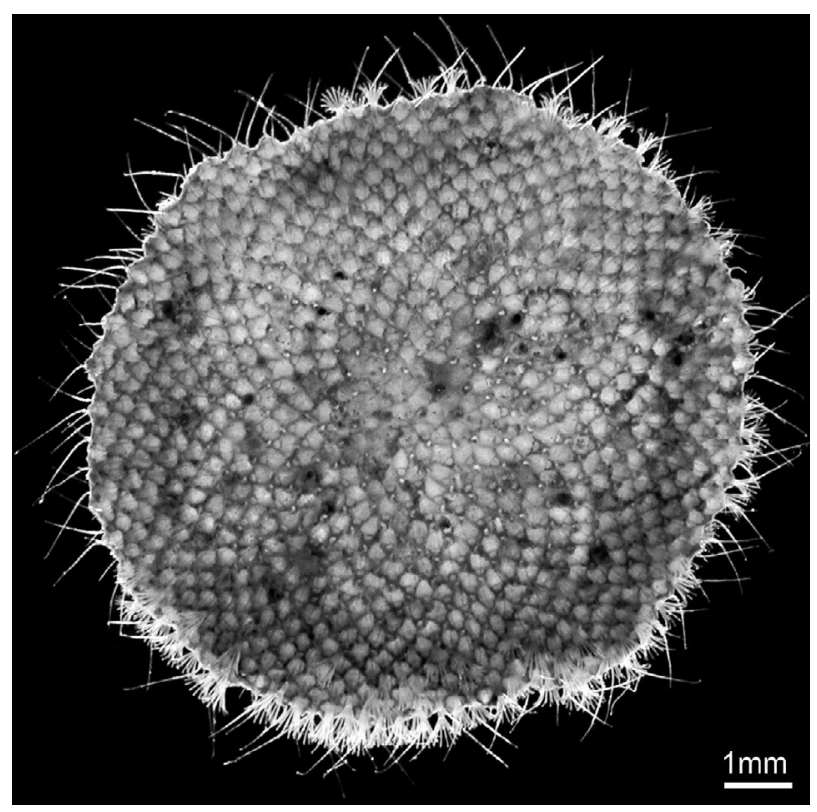

Fig. 1. Living colony of Cupuladria biporosa from the Gulf of Chiriqui showing marginal vibracula and feeding zooids

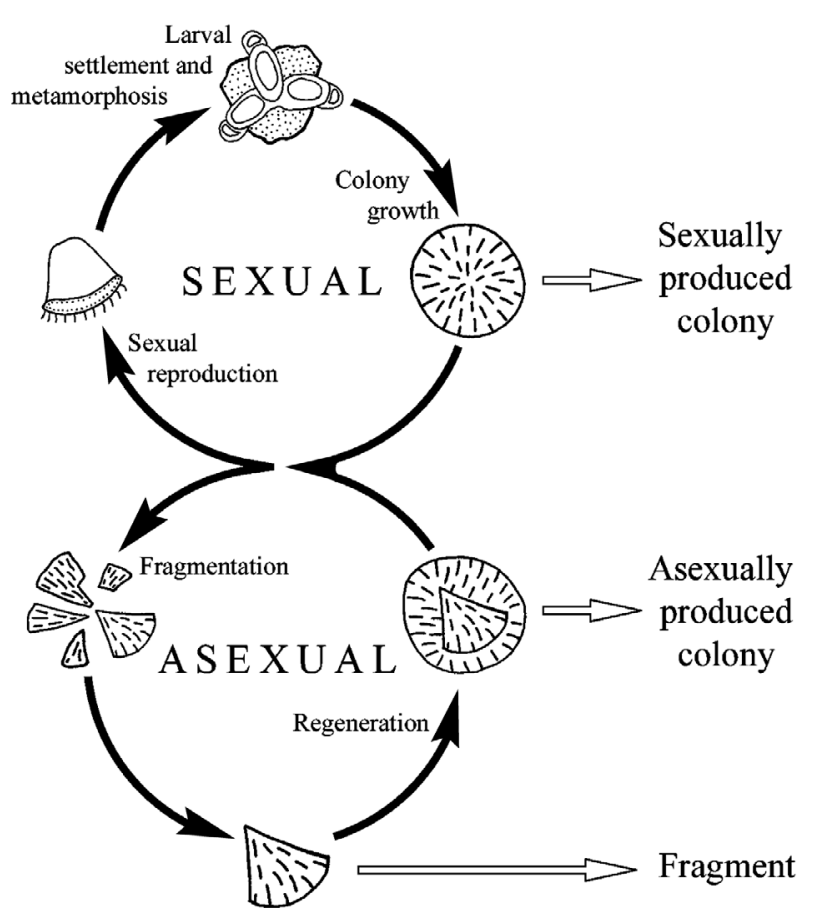

Fig. 2. Simplified cupuladriid life cycle illustrating the potential to propagate both sexually and asexually. Text to the right indicates the type of forms easily determined from cupuladriid assemblages such as those studied here

1985, Winston 1988, Cook \& Chimonides 1994, Thomsen \& Håkansson 1995, Håkansson \& Thomsen 2001, Dick et al. 2003).

With most plants or animals that are able to propagate asexually it can be extremely difficult to retrospectively determine the reproductive mode in which an individual originated. Cupuladriid bryozoans, however, unambiguously preserve their mode of propagation in the morphology of their carbonate skeletons (Fig. 3) (Marcus \& Marcus 1965, Winston 1988, Thomsen \& Håkansson 1995, Håkansson \& Thomsen 2001). Thus, it is possible to quantitatively measure the prevalence of asexual propagation in a living or fossil population without making assumptions about growth strategy (e.g. Lee \& Noble 1990) or having to assess the genetic structure of a population, as is often necessary in other organisms (e.g. Harrison \& Wallace 1990).

Cupuladriids are well suited to the direct empirical testing of hypotheses concerning the ecological and evolutionary patterns of life history variation in both time and space, since large amounts of data can be collected from both dead and fossil material. Despite this potential, surprisingly little work has detailed the prevalence of varying reproductive life histories in cupuladriids, or has examined in detail the mechanical and biological processes of fragmentation which are 


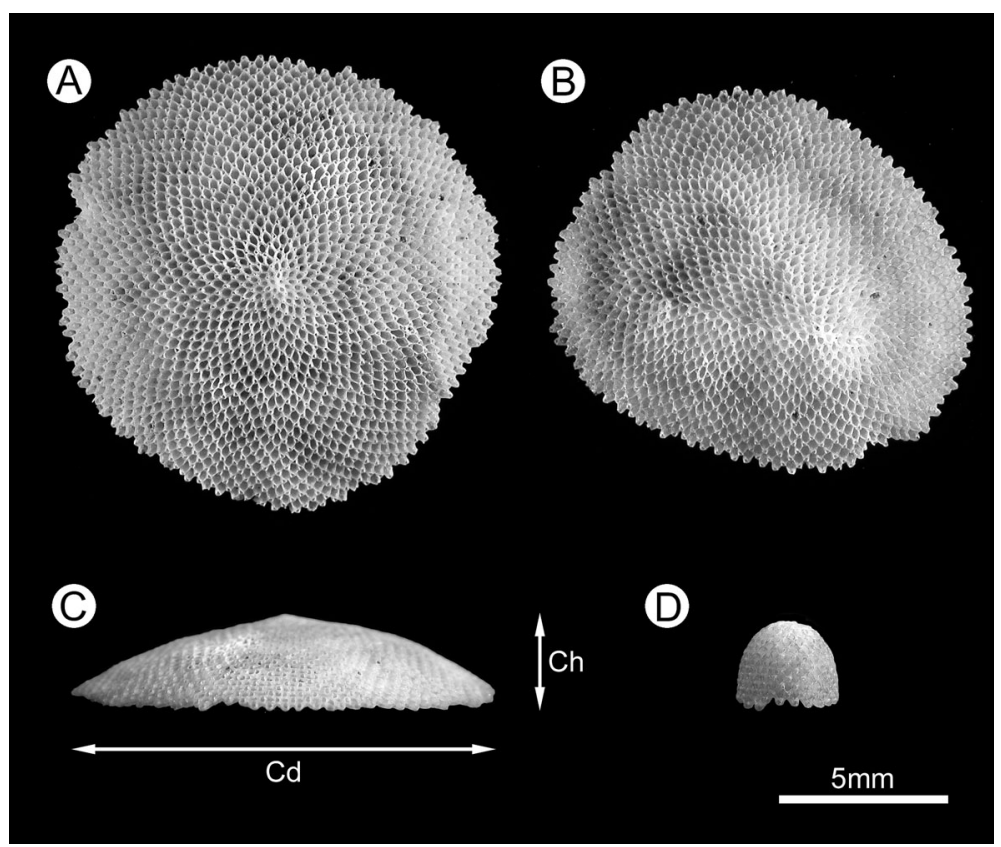

Fig. 3. Cupuladriid reproductive and colony life histories. (A) Sexually produced colony of Cupuladria 5 biporosa from Gulf of Chiriqui, Panama. (B) Asexually produced colony of Cupuladria 5 biporosa from Gulf of Chiriqui, Panama. (C) Lateral view of the colony in (A) showing flat discoidal nature and the measurement of colony diameter $(\mathrm{Cd})$ and colony height (Ch). (D) Lateral view of colony of Cupuladria 1 from San Blas, a species that produces small highly domed colonies with determinate growth

\section{Cupuladriid biology}

Cupuladriids today are generally restricted to sandy and muddy sediments free of sea grass and coral in tropical and subtropical upper bathyal and neritic zones around the world (Cook \& Chimonides 1994 and references therein). They originated in the Paleocene, and since the Miocene have become an important member of the filter-feeding sandy bottom fauna (Cook \& Chimonides 1983), often occurring as thousands of colonies in both fossil and Recent samples (Winston 1988).

In an assemblage of co-existing cupuladriids from Florida, Winston (1988) demonstrated differences in the proportion of sexually to asexually recruited colonies between populations of 2 cupuladriid species. Cupuladria doma was maintained mostly by sexual reproduction with only around $3 \%$ of colonies being produced asexually. In contrast, Discoporella umbellata was composed of around $50 \%$ of colonies that had been recruited asexually. These differences in life history appear to correlate with basic differences in colony morphology between the 2 spe-

essential for understanding the adaptive processes responsible for different life history strategies.

Asexual propagation by fragmentation in corals, for example, is considerably better understood (Highsmith 1982). A number of studies have measured the importance of asexual propagation in coral communities (e.g. Tunnicliffe 1981, Lasker 1990, Lee \& Noble 1990, Lewis 1991, Smith \& Hughes 1999), have described the biological and ecological consequences of fragmentation upon colonies (e.g. Highsmith 1982, Lasker 1984), and have revealed specific mechanical strategies that enhance, and even control, fragmentation (e.g. Boller et al. 2002).

Here we use data from a large-scale bottom survey from both the Pacific and Caribbean coasts of Panama to explore the reproductive life histories of cupuladriid species. First, our approach incorporates the recent taxonomy and phylogeny of Central American cupuladriids to document the prevalence of particular life history strategies. Second, we use environmentally heterogeneous study areas within which the potential mechanisms controlling phenotypic variation in cupuladriid life histories can be examined. Third, we compare measures of life history variation against morphologies in species to further understand the mechanisms of asexual propagation in cupuladriids. cies. C. doma produces more robust, generally smaller and more compact colonies than D. umbellata, implying that colonies of $C$. doma invest in greater protection from fragmentation while $D$. umbellata invests less in colony protection with the consequence of increasing the likelihood of fragmentation (Winston 1988).

Thomsen \& Håkansson (1995) and Håkansson \& Thomsen (2001) documented the ratio of sexual to asexual propagation in a number of free-living bryozoans from the Cretaceous to the Recent. These studies revealed that free-living bryozoans employ a wide range of reproductive strategies both across lineages and throughout the geological history of clades. Some species were found to propagate mostly sexually while others propagate mostly via asexual means. Akin to Winston's findings, the authors found that broad morphological differences between species appear to play an important role in the potential of colonies to fragment, and therefore a direct energetic trade-off between colony protection and asexual propagation was proposed.

Despite these studies, the mechanisms and processes accounting for patterns of asexual propagation in free-living bryozoans remain speculative due to a dearth of empirical testing and large scale data sets. The relationships between colony morphology and 
reproductive life history within species has thus far been based on informed guess and the relative importance of phylogeny upon constraining the amount of variation in mode of propagation within taxa remains unstudied.

\section{Central American cupuladriid taxonomy and phylogeny}

This study was conducted in conjunction with a detailed taxonomic survey of the Cupuladriidae of the south western Caribbean and Tropical eastern Pacific involving molecular (Dick et al. 2003) as well as morphometric approaches (A. Herrera Cubilla et al. unpubl.).

Using 16S mitochondrial rDNA from colonies collected on both sides of the isthmus, a total of 9 monophyletic cupuladriid haplotype species were described. These comprised 1 Cupuladria and 3 Discoporella species on the Pacific side and 2 Cupuladria and 3 Discoporella species on the Caribbean side. Phylogenetic analysis revealed that both Cupuladria and Discoporella maintain a sister clade (a pair of geminate species) across the isthmus (Dick et al. 2003).

Detailed morphometric analysis from cupuladriid colonies from either side of the isthmus confirmed the discrimination of the 3 Cupuladria haplotype species defined through molecular analysis, and established 3 further Cupuladria species in the Caribbean (A. Herrera Cubilla et al. unpubl.). Similar preliminary morphometric approaches applied to the Discoporella species have so far identified 2 of the Caribbean haplotype species of Dick et al. (2003) and established a fourth not collected by the molecular survey (A. Herrera Cubilla et al. unpubl.). In the Pacific, the cryptic species group Discoporella 3A, 3B and 3C suggested by Dick et al. (2003) morphometrically resolves to 2 species composed of the haplotypes $3 \mathrm{~A}$ and 3B/3C.

Molecular and morphological approaches to Central American cupuladriid taxonomy therefore agree except upon the splitting the Pacific Discoporella 3 group. For the purposes of this study we followed the recommendations of the morphometric approach. All species used in this study are nonetheless preliminary, awaiting formal classification.

\section{The study system}

From a marine ecological perspective, the Isthmus of Panama is a barrier between the Pacific and the Atlantic. Its formation resulted in the interruption of water flow between the western Caribbean and tropical eastern Pacific approximately 3 to 4 million yr ago (Coates \& Obando 1996, Coates et al. 2003). As a result, the Pacific and Caribbean coasts of Panama are considerably different marine environments today (Jackson \& D'Croz 1997). The Pacific coast normally experiences strong upwelling events from around January to April as a result of the shifting trade winds across the region that bring deep nutrient-rich waters into surface and coastal regions, substantially reducing temperatures and driving a bloom in primary production. Conversely, the Caribbean coast of Panama experiences no upwelling events (D'Croz et al. 1991).

As a result, 3 key cross-isthmus distinctions can be made. (1) In general, the coastal waters on the Pacific side of Panama are considerably more productive than on the Caribbean. (2) The Pacific coast is more environmentally unstable than the Caribbean. Increased instability on the Pacific coast occurs on a seasonal time-scale as temperature and nutrient levels fluctuate due to the upwelling, and on an inter-annual timescale as the normal seasonal cycles are intermittently interrupted by El Niño events that can suppress upwelling. (3) The Caribbean is ecologically more complex, with a much wider range of habitats than the eastern Pacific.

Notwithstanding these general patterns, there are sizeable differences between regions within each coast. For example, upwelling along the Pacific coast of Panama occurs only in areas where low-lying land permits the triggering winds to pass. Thus, upwelling occurs in the east in the Gulf of Panama (Fig. 4) while the Gulf of Chiriqui in the west (Fig. 4) is protected from such winds by the mountainous region in west of the country (the Cordillera de Talamanca) and consequently does not experience direct upwelling. Although the whole Caribbean coast experiences little seasonal variation in temperature, the Bocas del Toro region (Fig. 4) is characterised by some seasonal variations in primary productivity due to variations in rainfall and hence terrestrial runoff (Smithsonian Tropical Research Institute Marine Sciences Environmental Program unpubl.) while the San Blas region in the east experiences very little variation in nutrient levels and remains environmentally stable.

Thus, the coasts of Panama can be split into marked regions based upon levels of primary productivity and gradients of environmental stability that subsequently control gross ecological parameters (Fig. 5)

Many taxa are represented by different numbers of species on either side of the isthmus today, but the pattern is not always clear or 1-way. Thus, corals (Glynn 1982, Budd 2000), sponges (Soest 1994), encrusting bryozoans (Cheetham \& Jackson 2000) and foraminifera (Collins 1999) are more diverse in the Caribbean than eastern Pacific, while Molluscs (Roy et al. 2000), Crustacea (Jones \& Hasson 1985) and echinoderms (Chesher 1972) appear to be roughly as diverse in both oceans. 


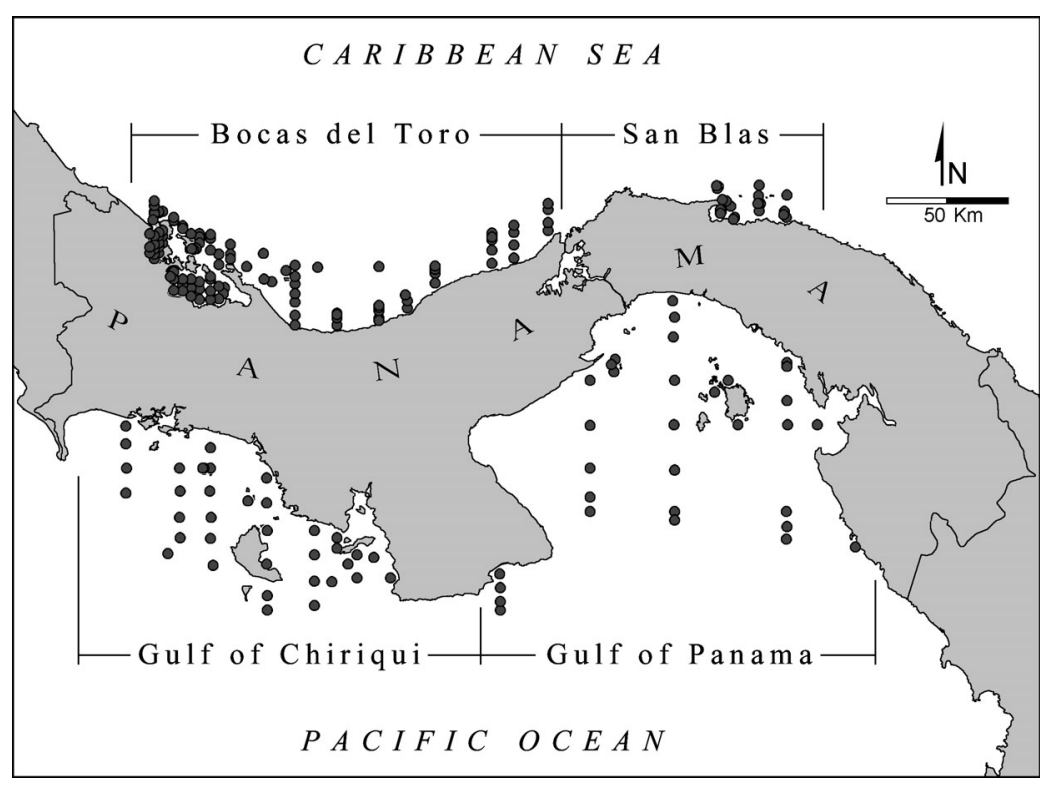

Fig. 4. The Isthmus of Panama illustrating regional separations used in this study and location of dredge samples (•)

\section{Life history predictions}

We hypothesised that we might be able to predict patterns of sexual and asexual propagation in cupuladriid bryozoans across and around the Isthmus of Panama given what we know about the ecology and environment across the region. Comparing patterns of species abundances, distributions and occurrences across environments and ecologies in this way may provide clues as to what processes have led to the present day variations in life histories of cupuladriids.

Greater productivity may increase levels of asexual propagation as growth in bryozoans increases in re-

\section{Caribbean Sea}

\begin{tabular}{l|l} 
Bocas del Toro & San Blas \\
- No upwelling & - No upwelling \\
- Low seasonality & Moderate to low productivity \\
- Very low seasonality \\
- Environmentally heterogeneous & : Environmentally homogeneous \\
$\begin{array}{l}\text { Seagrass, mud, mangrove and } \\
\text { reef dominated }\end{array}$ & - Reef dominated \\
\end{tabular}

\section{Isthmus of Panama}

\section{Gulf of Chiriqui}

- Weak upwelling

- Low seasonality

- Moderate to high productivity

- Environmentally homogeneous

- Poor reef development

\section{Gulf of Panama}

- Strong upwelling

- Very high seasonality

- Very high productivity

- Environmentally homogeneous

- Poor reef development

\section{Pacific Ocean}

Fig. 5. Fundamental environmental and ecological characteristics of the 4 regions around the Isthmus of Panama sponse to increased food (Winston 1976, Jebram 1977, O'Dea \& Okamura 1999) and asexual propagation is related to growth (Cheetham et al. 2001, Håkansson \& Thomsen 2001). This may operate on 2 levels each with different predictable outcomes. First, species or taxa that rely on growth as a mode of propagation may be better adapted to environments with higher levels of food, while taxa that rely less on growth and more on the production of larvae to propagate may be better adapted to lower food level environments. Thus, we can predict that we will find more species that rely on asexual propagation in the eastern Pacific than in the Caribbean as the eastern Pacific is more productive than the Caribbean and appears to have been so for at least 2 million yr (Collins 1996, Teranes et al. 1996, O'Dea \& Jackson 2002). Second, asexual propagation could be enhanced in areas of increased food on an eco-phenotypic rather than an adaptive or genetic level. If this were the case, we would expect to observe greater fragmentation in populations from areas of high productivity compared to another population of the same species from areas of low productivity, so long as genetic mixing between the populations exists. Thus, asexual propagation should be greater in colonies from Bocas del Toro than the San Blas in the Caribbean, and should be greater in colonies from the Gulf of Panama compared to colonies from the Gulf of Chiriqui in the Pacific.

Alternatively, cupuladriid reproductive life history strategies may be highly constrained by phylogenetic history. Using the phylogeny of Central American cupuladriids (Dick et al. 2002), we are now able to consider the importance of phylogeny by comparing the variation in reproductive strategies within and between clades.

\section{Life histories and colony morphology}

Gross morphology in cupuladriids is apparently linked to patterns of life history (Winston 1988, ,Cook \& Chimonides 1994, Håkansson \& Thomsen 2001), yet the relationships remain unquantified. For example, it has been hypothesised that species produce small, compact and heavily calcified colonies in order to sustain reduced fragmentation, while species that produce large, lightly calcified colonies are more likely to fragment with the possible intention of propagating 
asexually (Winston 1988, Cook \& Chimonides 1994, Thomsen \& Håkansson 1995, Håkansson \& Thomsen 2001). Within this study we investigate the relationships between morphology such as colony shape, colony size, zooid size and level of calcification and life history parameters such as fragmentation, regeneration and prevalence of asexual propagation.

\section{MATERIALS AND METHODS}

Collections. A total of 193 dredge samples were made between 1995 and 1998 on the Caribbean and Pacific coasts of Panama using the Smithsonian's R/V 'Urraca' (Fig. 4).

The 2 coasts of Panama were split into 4 regions (Fig. 4) based upon broad ecological and environmental differences. In the Caribbean, the Bocas del Toro region extends from the Archipelago de Bocas del Toro in the northwest of Panama along the Gulfo de Mosquitos to the exit of the Panama Canal. The San Blas region extends from the Canal eastwards along the Costa Arriba to the San Blas Province. On the Pacific side, the Gulf of Chiriqui region extends from the border of Costa Rica to the central edge of the Azuero Peninsula. The Gulf of Panama region ranges from the southeastern tip of the Azuero peninsula to the Darien.

A total of 109 dredge samples were made in the Bocas del Toro region, 20 in the San Blas, 33 in the Gulf of Chiriqui and 27 in the Gulf of Panama.

Dredge samples in all 4 regions were biased towards shallow waters. In Bocas del Toro the mean depth of dredge was $57 \mathrm{~m}$ and dredges ranged from 7 to $300 \mathrm{~m}$. In San Blas the mean depth was $41 \mathrm{~m}$ and ranged from 10 to $95 \mathrm{~m}$. In the Gulf of Chiriqui the mean depth was $93 \mathrm{~m}$ and ranged from 14 to $400 \mathrm{~m}$. In the Gulf of Panama the mean depth was $71 \mathrm{~m}$ and ranged from 6 to $380 \mathrm{~m}$.

For each dredge sample, material was sieved at 2 and $8 \mathrm{~mm}$ and all cupuladriid colonies and fragments of colonies from this fraction were picked. Eighteen of the dredge samples contained too many cupuladriids to complete all identifications and analysis. For these samples the cupuladriid assemblage was split into 8 equal parts, and 1 of these parts subsequently was fully analysed as a whole sample. Data on numbers of colonies and fragments in these sub-samples were then multiplied by 8 to estimate the total assemblage within the dredge sample.

Cupuladriids in each dredge sample were bleached, cleaned, identified and counted. Each specimen was then examined to determine its mode of origin (Figs. 2 \& 3). Those with an ancestrula had derived from a sexually produced larvae and were therefore classed as 'sexually produced colonies' (e.g. Fig. 3A). Colonies that showed any sign of regeneration from a previous fragment (no matter how small) were classed as 'asexually produced colonies' (e.g. Fig. 3B). A number of colonies were found to have both an ancestrula and evidence of fragmentation and regeneration. These colonies were classed as sexually produced colonies with evidence of asexual growth for fragmentation and regeneration analysis. Colonies derived via budding of a parent colony (Marcus \& Marcus 1962) were classified as asexually recruited colonies but otherwise not separated for this study due to their rarity.

All remaining specimens preserved no evidence of their mode of propagation and were classified simply as 'fragments' (Fig. 2). Fragments could have arisen through a number of processes; colonies could have fragmented while alive and not subsequently been able to regenerate, or colonies could have fragmented after death either in the sea prior to collection, during collection, during sorting, transportation, cleaning or archiving.

We investigated the material on a number of levels. Data were pooled into the following groups: oceans (Caribbean and Pacific), regions (Bocas del Toro, San Blas, Gulf of Chiriqui and Gulf of Panama), genera (Cupuladria and Discoporella) and species (each species).

Diversity, abundance and occurrence. Data on the abundance of cupuladriids were gathered by counting only the number of colonies. Percentage occurrence data on the other hand included both colonies and fragments. Only 5 of the dredge samples where found to contain fragments and no colonies. Abundance and percentage occurrence in dredge samples were calculated for each genus and species. $\chi^{2}$ was used to measure differences between the percentage occurrence of the 2 genera across oceans and regions.

Species richness was determined within individual dredge samples, sampling regions and oceans. Because the numbers of dredge samples differed greatly among regions and oceans, it may be possible that our measure of diversity (species richness) could simply reflect sampling intensity. In order to assess the quality of sampling we compiled species accumulation curves for each region and each ocean. Accumulation curves were created using Estimates 6 (Colwell 1997), which randomises the order of sampling to create a curve representing richness levels at varying sampling efforts (number of collections made). Repeating this process 50 times produced mean values that remove the bias of sampling order. Sampling completeness could then be estimated by observing the nature of the species accumulation curves and their closeness to an asymptote (Thompson \& Withers 2003).

Mode of propagation, fragmentation and regeneration. The ratio of sexual to asexual propagation was assessed by calculating the percentage of colonies pro- 
duced sexually and was determined separately within oceans, regions, genera and species. Among the same levels we calculated the degree of both fragmentation and regeneration as indices. Fragmentation index is a measure of how easily colonies fragment and was calculated by the proportion of colonies showing signs of fragmentation to those colonies showing no evidence of fragmentation. Some ecological and physical processes may confound this estimate, but we feel that it represents a clear assessment of how likely colonies fragment. Regeneration index was calculated by determining the proportion of colonies showing evidence of regeneration following fragmentation to the number of fragments, which, by definition, are cupuladriids that do not show any signs of regeneration. This index therefore estimates the ability of colonies to regenerate following fragmentation.

As the proportion of sexually recruited colony data, fragmentation and regeneration indices were calculated as proportions it was necessary to arcsine-square root transform the data to correct for non-normality prior to parametric statistical analysis. $\chi^{2}$ contingency tables were used to assess differences in the proportion of sexually recruited colonies and the indices of fragmentation and regeneration among oceans, regions, and genera. In addition, to investigate the effects of disturbance upon mode of propagation we looked for a correlation between depth and fragmentation index within all species in all dredges.

Species morphologies. To investigate the importance of colony morphology upon the reproductive life histories in cupuladriids, 20 larvally recruited colonies were randomly selected from the total assemblage of each species by assigning sequential numbers to colonies and using random number tables to make selections. Each selected colony was measured for maximum and minimum diameter (Fig. 3). The 2 colony diameters vary in relation to the symmetry of growth. We also measured colony height, which by dividing by median colony diameter provided an index of colony shape that was then averaged for each species. Colony shape index increases as colonies become less flat and more domed (Fig. 3). Prior to statistical analysis, colony shape data were square root transformed due to a non-normal distribution.

During our collections we noted that Central American cupuladriids have extremely wide ranging levels of calcification. Level of calcification in bryozoans depends upon a number of factors including the thickness of zooidal walls, the number of, thickness and morphology of specialised structural zooids (kenozooids) and the degree of secondary calcification (McKinney \& Jackson 1989). In the cupuladriids the level of calcification appears to be controlled mostly by degree of basal calcification (Cook \& Chimonides 1994) and less so by size of zooids and levels of zooidal secondary calcification. We wanted to quantitatively measure levels of calcification among species to investigate its relationship with other life history parameters. To do this, the 20 randomly selected colonies used for colony morphology measures were weighed in total.

The growth of each separate colony was assumed to model an empty cone. The total upper surface area of each colony could therefore be calculated using the formula:

Upper surface area of cupuladriid colony =

$$
(\pi \times r) \sqrt{\left(r^{2}+h^{2}\right)}
$$

where $r=$ median colony radius and $h=$ colony height.

For each species we were then able to determine an index of the level of calcification by dividing the total weight by the sum surface areas for all twenty colonies. This gave a calcification index (Ci) in $\mathrm{mg} \mathrm{mm}^{-2}$ for each species which reflects the density of calcification per surface area of colony.

Relations between morphologies and life histories. One of our aims was to measure the patterns between the reproductive life histories and colony morphologies observed among cupuladriid species. To test hypotheses of the effects of colony morphology on reproductive life history factors, we made correlations between species life history data (\% sexually recruited colonies, fragmentation and regeneration indices) and average species colony morphology data (maximum colony diameter, mean colony shape, mean zooid size and $\mathrm{Ci}$ ) using the Pearson Product Moment Correlation Coefficient (r). Strengths of relationships between life history and colony morphology measures were tested for significance using a $t$-test.

To explore the geographic and phylogenetic patterns and colony morphologies among cupuladriid species we used Detrended Correspondence Analysis (DCA) to plot species on independent axes of decreasing variation. DCA is similar to Principal Components Analysis but is nonparametric. MVSP v3.1 (Kovach 1998) was used to calculate all ordinations. For each species, we included mean colony shape, maximum colony diameter, $\mathrm{Ci}$, fragmentation index, regeneration index and percentage of colonies of sexual origin into DCA. For this purpose, it was assumed that those species that showed no fragmentation had a regeneration index of zero.

\section{RESULTS}

\section{Patterns of cupuladriid diversity, occurrence and abundance}

A total of 12 preliminarily named cupuladriid species were identified, 9 in the Caribbean (Cupuladria 1, Cupuladria 3, Cupuladria 9, Cupuladria 4 biporosa, Cupu- 
ladria 6 surinamensis, Discoporella 5, Discoporella 4, Discoporella 2, Discoporella 7) while just 3 in the Pacific (Cupuladria 5 biporosa, Discoporella 3B/3C, Discoporella 3A) (Table 1). Of the 9 Caribbean species, all were found in Bocas del Toro while 6 (Cupuladria 1, Cupuladria 9, Cupuladria 4 biporosa, Cupuladria 6 surinamensis, Discoporella 1, Discoporella 7) were found in the San Blas. All 3 Pacific species were found in the Gulf of Panama while 2 (Cupuladria 5 biporosa, Discoporella 3B/3C) were found in the Gulf of Chiriqui (Table 1). Species names relate to synonymous haplotype groups found by Dick et al. (2002).

Species accumulation curves (Fig. 6) reveal cupuladriid collections on both sides of the isthmus to be extremely well sampled. Both the Caribbean and the Pacific reached an asymptote within our sampling intensity (Fig. 6A). At the regional level, our sampling was complete in the Pacific with both regions easily reaching an asymptote. In the Caribbean, sampling was adequate in Bocas del Toro (Fig. 6B) but comparatively inadequate in the San Blas region to confidently calculate true species richness (Fig. 6B); the accumulation curve for the San Blas demonstrates the clear lack of an asymptote.

Accordingly, we must be cautious about assuming that the San Blas has less cupuladriid species than Bocas del Toro. In order to address this problem, we measured the average species richness in Bocas del Toro under a sampling intensity similar to that used in San Blas using the EcoSim program (Gotelli \& Entsminger 2001). EcoSim uses a series of randomisations

Table 1. Cupuladriid species found in dredge samples collected in this study around the Isthmus of Panama with the percentage occurrence in dredge samples, the number of colonies and the number of fragments collected of each

\begin{tabular}{|lccc|}
\hline & $\begin{array}{c}\text { \% occurrence in } \\
\text { dredge sample }\end{array}$ & $\begin{array}{c}\text { No. of } \\
\text { colonies }\end{array}$ & $\begin{array}{c}\text { No. of } \\
\text { fragments }\end{array}$ \\
\hline Caribbean & & & \\
Cupuladria 1 & 5.4 & 129 & 0 \\
Cupuladria 3 & 7.8 & 681 & 156 \\
Cupuladria 9 & 1.6 & 608 & 191 \\
Cupuladria 4 biporosa & 43.4 & 4117 & 2628 \\
Cupuladria 6 surinamensis & 32.6 & 3180 & 3961 \\
Discoporella 5 & 12.4 & 805 & 42 \\
Discoporella 4 & 10.9 & 1103 & 0 \\
Discoporella 2 & 10.9 & 3453 & 387 \\
Discoporella 7 & 1.6 & 92 & 14 \\
Mean & 14.0 & & \\
SD & 14.4 & & \\
Pacific & & & \\
Cupuladria 5 biporosa & 41.7 & 642 & 663 \\
Discoporella 3B/3C & 48.3 & 7404 & 1202 \\
Discoporella 3A & 3.3 & 477 & 1197 \\
Mean & 31.1 & & \\
SD & 24.3 & & \\
\hline
\end{tabular}

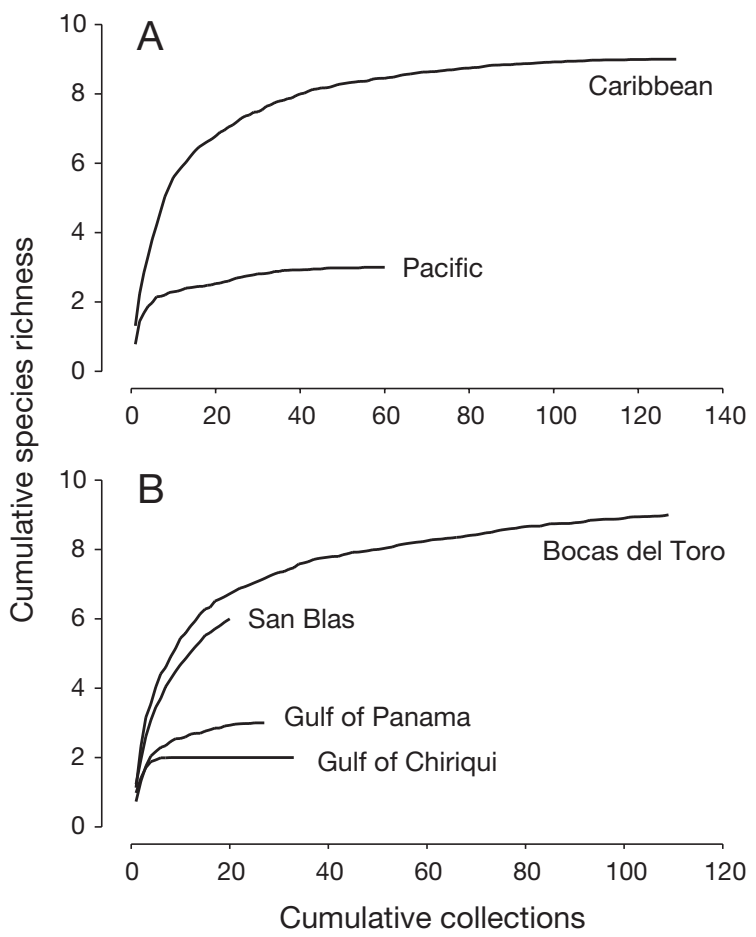

Fig. 6. Cupuladriid species accumulation curves for (A) oceans and $(\mathrm{B})$ regions

to calculate a mean species richness within an assemblage when it is sampled at any effort less than the level actually sampled. For this exercise, we used number of colonies found as the measure of sampling effort rather than number of dredges because the dredges varied so much between regions. Under a sampling effort of 418 colonies, mean species richness in Bocas was estimated at 8.5, just slightly reduced from the actual 9 species. The lower $95 \%$ confidence limit was calculated to be 7 species. Thus, at similar sampling intensity Bocas del Toro still has more species than the San Blas, and we can therefore confidently accept that the cupuladriids of San Blas are less diverse than Bocas del Toro.

Fig. 7 shows trends in diversity across levels ranging from individual dredge samples, region and ocean among Caribbean and eastern Pacific cupuladriids. Maximum richness in the eastern Pacific is constant through the levels, showing that species tend to be well distributed and common. In the Caribbean, the maximum richness consistently increases through the levels and there is a considerable increase in mean richness between values at the sample and regional levels (Fig. 7). Thus, many Caribbean species are restricted in distribution. It is unlikely this is the result of poor sampling given the completeness of sampling in the Caribbean (Fig. 6). 


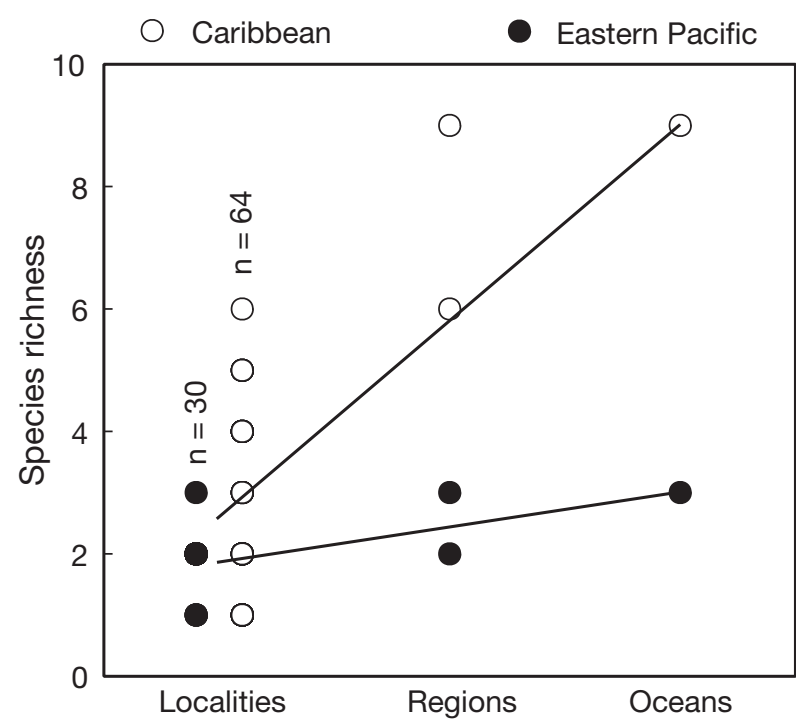

Fig. 7. Changes in cupuladriid species richness at the level of dredge localities, regions and oceans in both the Caribbean and Pacific coasts of Panama. Lines are drawn from mean locality diversity to total ocean diversity representing the nature of species distributions

Cupuladriids were found in $48.7 \%$ of all the 193 dredge samples. The percentage occurrences of the 2 genera on either side of the isthmus was significantly different $\left(\chi^{2}=5.104, \mathrm{df}=1, \mathrm{p}<0.05\right)$. In the Caribbean, Cupuladria is the most common genus occurring in $41.6 \%$ of dredges while Discoporella occurs in only $25.6 \%$ of dredges. In the Pacific, the trend is opposite although not as striking, with Discoporella occurring in $48.3 \%$ and Cupuladria occurring in $41.7 \%$ of the dredges (Table 2). The percentage occurrences between the 2 genera varies significantly among the 4 regions $\left(\chi^{2}=15.71\right.$, df $\left.=3, p<0.001\right)$ and each region mirrors the trends for their respective oceans (Table 2).
The percentage occurrence of any cupuladriid found within a dredge does not vary significantly $\left(\chi^{2}=3.39\right.$, $\mathrm{df}=3, \mathrm{p}=0.335$ ), around $50 \%$ of the dredges were found to yield cupuladriids in each of the regions (Table 2).

The percentage occurrence of each species is listed in Table 1. In the Caribbean, Cupuladria 4 biporosa and Cupuladria 6 surinamensis dominate while in the Pacific Cupuladria 5 biporosa and Discoporella 3B/C dominate.

In total, 22898 cupuladriid colonies and 9077 fragments were collected. Total abundances across regions were related to sampling effort, with most colonies being found in Bocas del Toro (Table 2). The relative abundances of the 2 genera across the regions reveal significant differences. In both of the Caribbean regions, the proportion of Cupuladria to Discoporella colonies is significantly higher than in either of the Pacific regions where Discoporella dominates throughout $\left(\chi^{2}=147.792\right.$, df $\left.=3, \mathrm{p}<0.001\right)$ (Table 2 ).

The mean number of colonies found in each dredge varied between the 4 regions (Table 2). From this data, densities of cupuladriids appear to be considerably greater in Bocas del Toro than San Blas, although this may reflect the differential sampling effort between the regions. Nevertheless, patterns of occurrence and abundance correlate across the 12 species ( $r=73.5$, $\mathrm{p}<0.01$ ) (Fig. 8). Thus, species that are commonly occurring are generally also abundant. In the Caribbean the 2 most commonly occurring species ( $\mathrm{Cupu}$ ladria 4 biporosa and Cupuladria 6 surinamensis) are also the most widely distributed and the most abundant (Table 1). Similarly, in the Pacific, Discoporella $3 \mathrm{~B} / \mathrm{C}$ is the most commonly occurring species, while also being the most widely distributed and the most abundant. Two species, Discoporella 2 in the Caribbean and Cupuladria 5 biporosa in the Pacific show a

Table 2. Occurrence, abundance and life history variables of cupuladriid bryozoans around the Isthmus of Panama grouped into oceans, regions and genera. Frag.: fragmentation; Regen.: regeneration

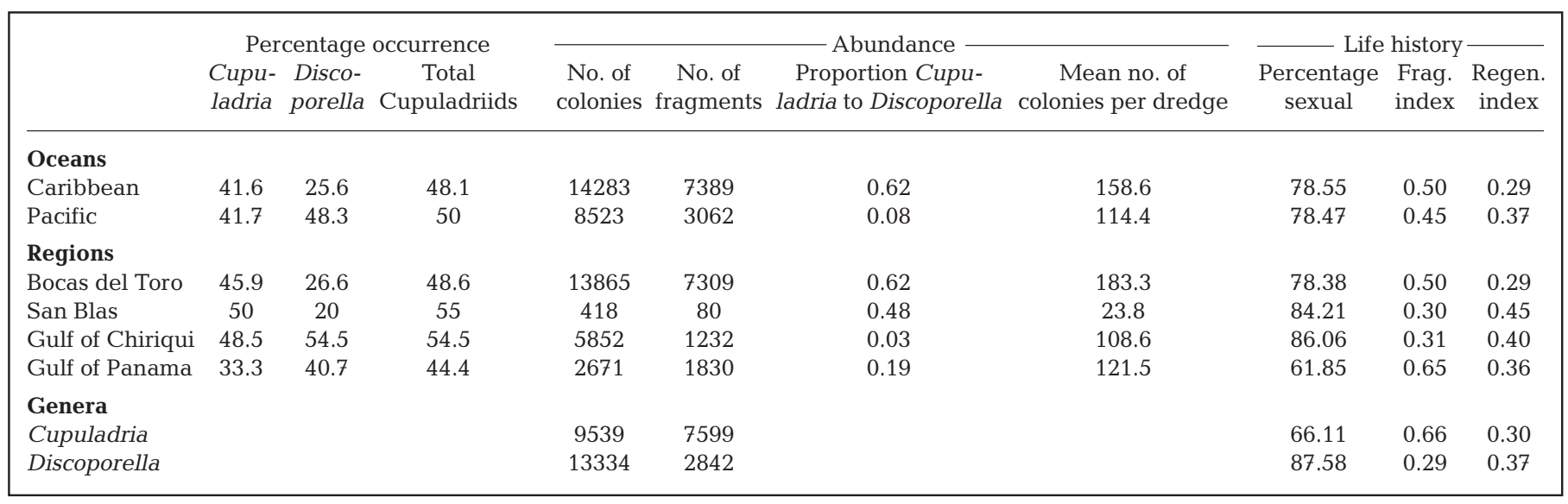




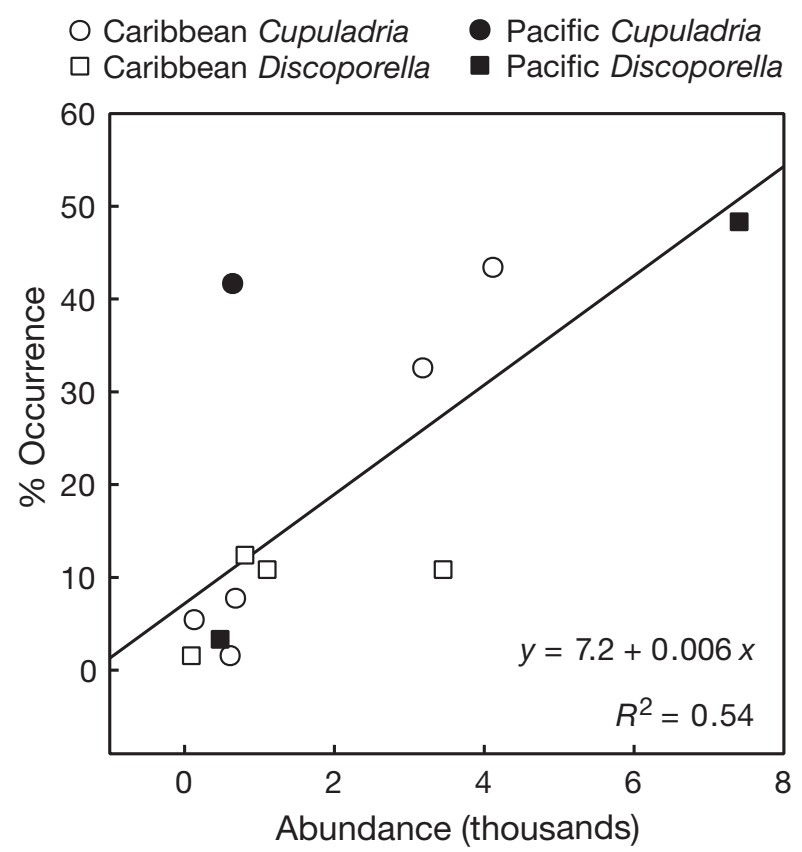

Fig. 8. Abundance and percentage occurrence of individual cupuladriid species from the Caribbean and Pacific coasts of Panama

deviation from this trend. Discoporella 2 is well distributed all along the Caribbean coast, but only occurs in a small number of dredges. When it does occur, however, it is very abundant (Table 1). On the other hand, Cupuladria 5 biporosa is widely distributed, occurring in many samples along the whole Pacific coast, but consistently is found in low numbers (Table 1).

\section{Species morphologies}

Both the mean and the range in maximum colony diameter in species across the oceans is similar (Table 3). However, cupuladriid species in the Pacific are substantially flatter than species in the Caribbean (Table 3). In addition, Caribbean species exhibit considerably more variation in their colony shapes while all Pacific species are roughly similar in shape (Table 3). Notably, the Pacific has no species with highly domed colonies like those found in the Caribbean (Table 3).

Mean zooid area is greater in the Caribbean than the Pacific (Table 3), mirroring trends observed in encrusting cheilostomes across the isthmus (Jackson \& Herrera 2000). Mean $\mathrm{Ci}$ of Caribbean species is greater than Pacific species although the range is somewhat similar (Table 3).

\section{Mode of propagation}

When all colonies from all species are pooled, the percentage of sexually recruited colonies in each ocean is remarkably similar at $78.6 \%$ in the Caribbean and $78.5 \%$ in the Pacific (Table 2). However, across the 4 regions, significant variations occur in the proportion of sexually recruited colonies $\left(\chi^{2}=20.358, \mathrm{df}=3, \mathrm{p}<\right.$ 0.01) (Table 2). The Gulf of Chiriqui has considerably more colonies derived through sexual recruitment $(86.1 \%)$ than the Gulf of Panama (61.9\%) (Table 2). In the Caribbean, Bocas del Toro has fewer colonies derived from sexual propagation $(78.4 \%)$ than the San Blas $(84.2 \%)$.

Table 3. Life history and related colony morphologies in cupuladriid species either side of the Isthmus of Panama. Diam.: diameter; Frag.: fragmentation; Regen.: regeneration; h: height; d: diameter; Ci: calcification index

\begin{tabular}{|c|c|c|c|c|c|c|c|}
\hline & $\begin{array}{l}\text { Percentage } \\
\text { sexual }\end{array}$ & $\begin{array}{l}\text { Frag. } \\
\text { index }\end{array}$ & $\begin{array}{l}\text { Regen. } \\
\text { index }\end{array}$ & $\begin{array}{l}\text { Max colony } \\
\text { diam. }(\mathrm{mm})\end{array}$ & $\begin{array}{l}\text { Mean colony } \\
\text { shape (h/d) }\end{array}$ & $\begin{array}{l}\text { Mean zooid } \\
\text { area }\left(\mathrm{mm}^{2}\right)\end{array}$ & $\begin{array}{c}\mathrm{Ci} \\
\left(\mathrm{mg} \mathrm{mm}^{-2}\right.\end{array}$ \\
\hline \multicolumn{8}{|l|}{ Caribbean } \\
\hline Cupuladria 1 & 100 & 0 & $\mathrm{n} / \mathrm{a}$ & 5.0 & 0.68 & 0.13 & 1.50 \\
\hline Cupuladria 3 & 83.6 & 0.34 & 0.42 & 8.2 & 0.34 & 0.11 & 1.11 \\
\hline Cupuladria 9 & 99.7 & 0.27 & 0.01 & 7.0 & 0.71 & 0.25 & 1.33 \\
\hline Cupuladria 4 biporosa & 60.1 & 0.65 & 0.38 & 13.1 & 0.23 & 0.15 & 0.52 \\
\hline Cupuladria 6 surinamensis & 69.0 & 0.72 & 0.20 & 7.9 & 0.52 & 0.22 & 0.74 \\
\hline Discoporella 5 & 97.5 & 0.07 & 0.32 & 7.0 & 0.39 & 0.22 & 1.41 \\
\hline Discoporella 4 & 100 & 0 & $\mathrm{n} / \mathrm{a}$ & 4.5 & 0.36 & 0.16 & 1.34 \\
\hline Discoporella 2 & 92.3 & 0.18 & 0.41 & 5.7 & 0.30 & 0.12 & 0.82 \\
\hline Discoporella 7 & 84.8 & 0.26 & 0.50 & 8.3 & 0.27 & 0.23 & 1.09 \\
\hline Mean & 87.4 & 0.28 & 0.32 & 7.41 & 0.42 & 0.18 & 1.10 \\
\hline $\mathrm{SD}$ & 14.6 & 0.26 & 0.17 & 2.54 & 0.18 & 0.05 & 0.34 \\
\hline \multicolumn{8}{|l|}{ Pacific } \\
\hline Cupuladria 5 biporosa & 25.4 & 0.89 & 0.42 & 7.1 & 0.28 & 0.13 & 0.81 \\
\hline Discoporella 3B/3C & 88.0 & 0.26 & 0.42 & 5.9 & 0.33 & 0.10 & 1.29 \\
\hline Discoporella 3A & 1.7 & 1.00 & 0.28 & 10.2 & 0.29 & 0.17 & 0.66 \\
\hline Mean & 38.4 & 0.72 & 0.37 & 7.73 & 0.30 & 0.13 & 0.92 \\
\hline $\mathrm{SD}$ & 44.6 & 0.40 & 0.08 & 2.22 & 0.03 & 0.04 & 0.33 \\
\hline
\end{tabular}


The percentage of sexually recruited colonies is highly significantly different between genera $\left(\chi^{2}=12.265\right.$, df $\left.=1, \mathrm{p}<0.001\right)$ when cupuladriids from both sides of the isthmus are combined, with $87.6 \%$ of Discoporella colonies being sexually produced and $66.1 \%$ of Cupuladria colonies being sexually produced. This is in contrast to the results obtained by Winston (1988), who found, albeit in only 2 species, that Discoporella propagates much more frequently through fragmentation than Cupuladria. The proportion of sexually produced colonies in species is therefore not controlled by which genera they belong to (Table 3, Fig. 9). No species were found to propagate exclusively through asexual means while 2 Caribbean species (Cupuladria 1 and Discoporella 4) were found to never propagate asexually; all their colonies were derived from a sexually produced larva. This phenomenon was not observed in any of the Pacific species which were all found to propagate asexually at some time (Fig. 9).

The mean percentage of sexually produced colonies compiled on a per species basis shows striking differences across the isthmus (Table 3, Fig. 9). The average percentage of sexually recruited colonies in Caribbean species is considerably greater $(87.4 \%)$ than Pacific species (38.4\%) (Table 3). Remarkably, the Caribbean has no species that produce over $50 \%$ of its colonies asexually, while conversely, 2 of the 3 Pacific species produce almost exclusively through asexual propagation (Table 3; Fig. 9).

\section{Fragmentation and regeneration}

Combining all cupuladriids, fragmentation index was found to be similar in the Caribbean (0.50) to the Pacific (0.45). Regeneration index was found to be less in the Caribbean (0.29) than the Pacific (0.37) (Table 2).

Across the 4 regions fragmentation indices were found to vary significantly $\left(\chi^{2}=34.172\right.$, df $=3$, p < 0.001). The Gulf of Panama had the highest fragmentation index while the lowest was observed in cupuladriids from the San Blas (Table 2). Regeneration indices were not significantly different among regions $\left(\chi^{2}=\right.$ 5.845, df $=3, p=0.119$ ) (Table 2). Cupuladria was found to have a greater index of fragmentation than Discoporella but the percentage of asexually recruited colonies is less in Cupuladria (Table 2).

Index of fragmentation of all cupuladriids within individual dredge samples did not decrease with increasing depth $(t=-0.425 ; \mathrm{df}=276 ; \mathrm{p}=0.671)$. It is unlikely that high energy levels from wave and current action are the primary causes of fragmentation.
Central American cupuladriid species exhibit fragmentation indices from zero to 1 (Table 3). Two species in the Caribbean (Cupuladria 1 and Discoporella 4) never fragmented and therefore had fragmentation indices of zero, while all colonies of 1 species in the Pacific (Discoporella 3A) showed signs of fragmentation and thus had a fragmentation index of 1 even though a small number of its colonies were originally recruited sexually. Mean fragmentation index on a per-species basis in Caribbean taxa was considerably less than in Pacific taxa (Table 3).

Indices of regeneration were found to vary much less than fragmentation across the species (Table 3). No species were found to regenerate all their fragments, although all species that fragmented were able to regenerate at least some of their colonies. Mean regeneration index was found to be similar in Caribbean and Pacific species (Table 3).

The life histories of the most abundant species in each ocean were compared between regions to look more closely at the ecological and environmental effects upon fragmentation. The Caribbean Cupuladria 4 biporosa has more sexually produced colonies and a reduced fragmentation index in the San Blas than in Bocas del Toro (Table 4). The eastern Pacific species Discoporella 3B/C has more sexually produced colonies and a reduced fragmentation index in the Gulf of Chiriqui than in the Gulf of Panama (Table 4). These trends mirror differences in gross levels of primary productivity between regions (Glynn 1982, D'Croz \& Robertson 1997, Smithsonian Marine Environmental Sciences Program unpubl.), with higher levels of asexuality in species occurring in those areas of relatively enhanced productivity. 
Table 4. Comparison of life history variation in cupuladriid species between regions. Mean percentage of sexual and asexually produced colonies, mean fragmentation rate and mean regeneration rate in dredges

\begin{tabular}{|lccc|}
\hline & $\begin{array}{c}\text { Mean\% } \\
\text { sexual }\end{array}$ & $\begin{array}{c}\text { Mean\% } \\
\text { asexual }\end{array}$ & $\begin{array}{c}\text { Mean fragmen- } \\
\text { tation index }\end{array}$ \\
\hline $\begin{array}{l}\text { Cupuladria 4 biporosa (Caribbean) } \\
\text { Bocas del Toro }\end{array}$ & 49.0 & 51.0 & 0.62 \\
San Blas & 64.8 & 35.5 & 0.39 \\
$\begin{array}{l}\text { Discoporella 3B/3C (Pacific) } \\
\text { Gulf of Chiriqui }\end{array}$ & & & \\
Gulf of Panama & 93.2 & 6.8 & 0.19 \\
& 79.0 & 21.0 & 0.29 \\
\hline
\end{tabular}

\section{Life history and colony morphology relationships among species}

Table 5 presents Pearson Product Moment Correlation Coefficients (r) between life history and morphology variables among both Caribbean and eastern Pacific cupuladriid species combined. The percentage of sexually recruited colonies is significantly positively correlated with $\mathrm{Ci}$, so that more heavily calcified species produce more of their colonies through sexual propagation. A positive correlation was found between the percentage of sexually recruited colonies and colony shape, although the relationship was not significant. However, maximum colony diameter was found to be negatively correlated with the percentage of sexually recruited colonies. Thus, species that produce large colonies are more likely to reproduce asexually.

Colony shape is significantly positively correlated with $\mathrm{Ci}$ and maximum colony diameter is highly significantly correlated with $\mathrm{Ci}$. Thus, species that produce highly domed, small colonies are generally more heavily calcified while colonies that produce flatter and wider colonies are less heavily calcified. Importantly, a highly significant negative correlation was found between $\mathrm{Ci}$ and fragmentation index (Fig. 10A). Thus, colonies of species that are heavily calcified fragment less often.
No significant relationship was found between colony shape and fragmentation index. Thus, we cannot accept the hypothesis that colonies of species that simply produce highly domed colonies are less likely to fragment. Fragmentation index is nonetheless highly significantly correlated with maximum colony diameter (Fig. 10B) so that species that produce wide colonies are more likely to fragment compared to colonies that have produce small colonies.

Colony shape is significantly correlated with the index of regeneration, suggesting that species that produce flatter colonies are more likely to be able to regenerate following fragmentation. It is likely, however, that this relationship is an artefact of the relationship between fragmentation and colony shape.

No correlation was found between the mean zooid area of species and any life history or colony morphology parameter even though zooid sizes vary considerably between cupuladriid species. No relationship was observed between mean zooid area and $\mathrm{Ci}$, enabling us to reject the theory that species that produce large zooids are less well calcified and are therefore more susceptible to fragmentation.

To further explore the relationships between the life histories and morphologies in cupuladriid species, the variables are represented in DCA space (Fig. 11). Axis 1 was found to account for $75.4 \%$ of the variation and is primarily determined by fragmentation index. Axis 2 accounts for only a further $5.1 \%$ of the variation and is primarily determined by both calcification index and regeneration index.

We marked species on their respective ocean and genera in an attempt to determine potential phylogenetic or environmental groupings. Thus we can assess the position of species in DCA space with respect to which ocean they are from and which gen-

Table 5. Pearson Product Moment Correlation Coefficient (r) between life history and morphology variables among all cupuladriid species, together with results of $t$-test for significance of relationship. Ci: calcification index ${ }_{i}^{* * *} \mathrm{p}<0.001{ }^{* * *} \mathrm{p}<0.01$; ${ }^{*} \mathrm{p}<0.05 ; \mathrm{ns}=$ non significant. $\mathrm{N}=12$ for all correlations except those against Regeneration index where $\mathrm{N}=10$ since 2 species never fragment. h: height; d: diameter

\begin{tabular}{|lccccc|}
\hline & $\begin{array}{c}\text { \% colonies } \\
\text { from larval } \\
\text { origin }\end{array}$ & Ci & $\begin{array}{c}\text { Colony } \\
\text { shape } \\
\text { (h/d) }\end{array}$ & $\begin{array}{c}\text { Maximum } \\
\text { colony } \\
\text { diameter }\end{array}$ & $\begin{array}{c}\text { Mean } \\
\text { zooid } \\
\text { area }\end{array}$ \\
\hline $\mathrm{Ci}$ & $0.78^{* *}$ & & & & $\begin{array}{c}\text { Fragmentation } \\
\text { index }\end{array}$ \\
Colony shape (h/d) & $0.53 \mathrm{~ns}$ & $0.57^{*}$ & & & \\
Max colony diameter & $-0.62^{*}$ & $-0.73^{* *}$ & $-0.45 \mathrm{~ns}$ & & $0.15 \mathrm{~ns}$ \\
Mean zooid area & $0.11 \mathrm{~ns}$ & $0.09 \mathrm{~ns}$ & $0.36 \mathrm{~ns}$ & $0.70^{* *}$ & $0.06 \mathrm{~ns}$ \\
Fragmentation index & $-0.88^{* * *}$ & $-0.83^{* * *}$ & $-0.41 \mathrm{~ns}$ & $0.48 \mathrm{~ns}$ & $-0.20 \mathrm{~ns}$ \\
Regeneration index & $-0.52 \mathrm{~ns}$ & $-0.55 \mathrm{~ns}$ & $-0.75^{*}$ & & $0.61^{*}$ \\
\hline
\end{tabular}


- Caribbean Cupuladria

- Caribbean Discoporella

- Pacific Cupuladria

- Pacific Discoporella

Fig. 10. Colony morphologies and reproductive life histories in cupuladriid species from the Caribbean and Pacific coasts of Panama. (A) Calcification index (Ci) against index of fragmentation. (B) Maximum colony diameter against index of fragmentation. Respective genera and ocean of each species are denoted. See Table 5 for the coefficients of functions
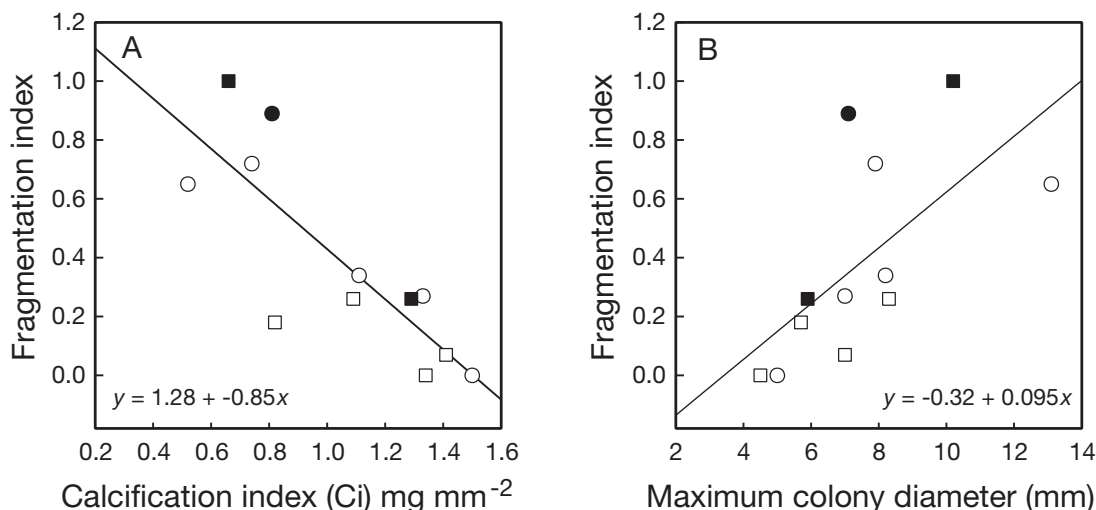

Maximum colony diameter $(\mathrm{mm})$ era they belong to. The 2 genera show similar ranges on both Axis 1 and 2. In contrast, there is a clear separation in the oceans (Fig. 11). The 3 eastern Pacific species are restricted to the upper right corner of DCA space, while the Caribbean species fill the rest of the space (Fig. 11).

\section{DISCUSSION}

\section{Patterns of cupuladriid diversity, occurrence and abundance}

In most Central American marine taxa, unequal rates of speciation and extinction occurring since closure of the Isthmus of Panama have resulted in differences in diversity between the eastern Pacific and Caribbean coast of Panama (e.g. Vermeij 1978, Lessios 1990, Jackson et al. 1996, Budd 2000). Even with the preliminary taxonomy used here, it is clear that cupuladriids are considerably more diverse in the Caribbean than the eastern Pacific, thereby following the transisthmian pattern of corals (Glynn 1982), sponges

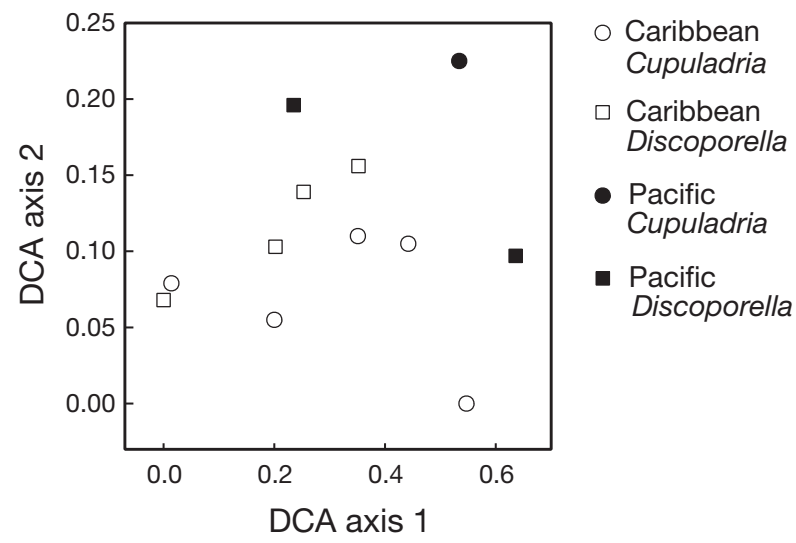

Fig. 11. Detrended Correspondence Analysis (DCA) of colony morphologies and reproductive life histories. Respective genera and ocean of each species are denoted
(Soest 1994), benthic foraminiferans (Collins 1999) and other cheilostome bryozoans (Cheetham \& Jackson 2000, Herrera \& Jackson 2000).

The Caribbean is typified by cupuladriid species that have both low abundances and occurrences and are restricted in distribution while Pacific species tend to be widely distributed and much more abundant (Fig. 6). This trend corroborates the results of molecular work showing restricted population distributions in Caribbean compared to Pacific cupuladriids (Dick et al. 2003), and both mirror the greater habitat heterogeneity that occurs along the Caribbean compared to Pacific coast of the isthmus.

One of the most striking patterns we observed was the generic dominance across the isthmus. In terms of both percentage occurrence and relative abundance, the Caribbean is dominated by the Cupuladria genus while the Pacific is dominated by the Discoporella genus (Table 2). The reason(s) explaining this divergence, however, remains elusive. No striking distinctions separating the 2 genera have been established in the literature, and as discussed later, the range of variation of life histories are similar in the 2 genera.

\section{Patterns of reproductive life history variation}

The percentage of sexually produced colonies and fragmentation and regeneration indices differ between the 2 genera, although the patterns are unclear. Cupuladria has a lower percentage of sexually produced colonies but has a higher index of fragmentation. This may in part be explained by the reduced index of regeneration observed in Cupuladria compared to Discoporella (Table 2). DCA reveals no clear distinction in the life histories between the genera that would help explain the differences in generic dominance on either side of the Isthmus of Panama (Fig. 11).

Thus, life histories appear not to be constrained phylogenetically, a suggestion supported by comparing the life histories of separate species; the variation 
observed in the percentage of sexually recruited colonies across all species reveals that levels of asexuality are irrespective of which genera a species belongs too. In fact, in the Pacific, the percentage of asexually produced colonies varies more between species of the same genus than all other species combined (Table 3). Even within the Discoporella 3 haplotype group (Dick et al. 2003) differences in reproductive and colony life histories occur. Discoporella 3A and Discoporella 3B/C have very different Ci's, maximum colony sizes, fragmentation indices and proportion of colonies derived via sexual propagation (Table 3), despite being closely related (Dick et al. 2003).

Patterns in life history are strongly divided across the isthmus. For instance, in the Cupuladria biporosa group, the Caribbean C. biporosa exhibits a much lower index of fragmentation than the Pacific C. biporosa and consequently has a greater percentage of its colonies produced via sexual propagation (Table 3). This pattern is also mirrored across all species. Caribbean species fragment less and are generally sexually produced while in the Pacific, species fragment more and are dominated by asexually produced colonies (Table 3). However, in 1 Pacific species this model is not sustained; Discoporella 3B/3C has a low index of fragmentation and a high incidence of sexually produced colonies. Nonetheless, the exceptionally low fragmentation indices observed in Caribbean species are not present in any of the Pacific species (Table 3).

When pooled within regions, significant life history differences occur between regions of the same oceans, and these provide support for the hypothesis that levels of asexual propagation should track levels of primary productivity. Thus, in the Caribbean, the level of asexual propagation is significantly higher in Bocas del Toro than the San Blas. The Bocas del Toro region is characterised by high levels of terrestrial run-off while the San Blas region does not have the same sized area of watershed (D'Croz \& Robertson 1997). Similarly, on the Pacific coast, levels of fragmentation and asexual propagation are considerably higher in the Gulf of Panama compared to the Gulf of Chiriqui. The Gulf of Panama experiences strong seasonal upwelling events that enhance levels of productivity considerably for about 3 or 4 mo a year, while no upwelling occurs in the Gulf of Chiriqui (D'Croz \& Robertson 1997).

Alternatively, this pattern may not be induced by environmental differences but may simply be due to different proportions of ecologically different species inhabiting the separate regions. In order to explore this question we compared the life histories of the commonest and most widespread species in each ocean by their respective region. In the Caribbean, the population of Cupuladria 4 biporosa shows a greater percentage of sexual recruits and reduced fragmentation indices in the nutrient poorer San Blas compared to Bocas del Toro (Table 4). On the Pacific side, Discoporella 3B/3C maintains a greater percentage of its colonies via asexual propagation and has an increased fragmentation index in the upwelling Gulf of Panama compared to the more nutrient poor Gulf of Chiriqui (Table 4).

Increased productivity can ecophenotypically increase the levels of asexual propagation in 2 ways. First, enhanced colony growth due to increased food availability (Winston 1976, Jebram 1977, O'Dea \& Okamura 1999) may simply increase the number of fragments produced within those species that can propagate via fragmentation. Second, fragmentation may not increase per se but the ability of a fragment to regenerate under an environment of enhanced food availability may increase. Thus, following fragmentation, a cupuladriid will have a smaller reserve of energy dedicated to colony growth compared to an unfragmented colony while correspondingly a relatively large area requiring regenerative growth. In addition, it is possible that fragments are exposed to a greater potential of disease and/or parasitism acquisition. A fragment able to easily derive all its requirements to counter such deleterious processes would therefore have a much better chance of survival, and the prevalence of asexuality in a population would correspondingly increase. Our data suggest, however, that the increased growth directly from increased food is more important. For relative levels of energies required for regeneration to be an important factor we would expect to see increased regeneration indices associated with increased fragmentation in the Pacific where food is higher than the Pacific. In fact, the opposite occurs both when all species are pooled (Table 2) and when individual species are separated (Table 4).

We propose that levels of primary production and hence food availability in the Pacific explain the transisthmian differences in cupuladriid life histories. Species that have flat and lightly calcified colonies are favoured in the Pacific, where food is high enough to sustain asexual propagation by fragmentation, while the low food levels in the Caribbean favour species that rely on propagation through the sexual production of larvae. Within this scenario we also have presented evidence that those species that do reproduce asexually are able to further increase propagation by fragmentation when inhabiting areas of enhanced food supply simply by increasing growth rates.

\section{Relationships between colony morphologies and life histories}

Fragmentation in species was found to be strongly influenced by the level of calcification and the maxi- 
mum size of colonies; species that produce wide and lightly calcified colonies break much more readily. Colony size is an index of growth strategy. Species that produce small colonies tend to have determinate growth, while species that produce large colonies tend to show no evidence of determinate growth. It seems fairly straightforward therefore to conclude that species that invest in incremental growth of the colony's margin do so to enhance asexual propagation, while species with determinately growing colonies tend to invest more heavily in energies for colony protection and larval production. This conclusion corroborates the patterns of life history observed in the field (see 'Discussion: Patterns of reproductive life history variation').

Fragmentation indices among species was statistically more significantly correlated with level of calcification than any other factor and colonies with high levels of calcification produce more highly domed colonies (Table 5). Colonies of highly domed species (e.g. Fig. 3D) are often extremely well-protected against fragmentation by extensive basal kenozooidal strengthening that produces 'filled-in' colonies (Cook \& Chimonides 1994). However, colony shape per se was found to have no significant influence upon fragmentation or level of asexual propagation, suggesting that the hypothesis that highly domed colonies are better protected against fragmentation because they roll around more easily may be untenable. Indeed, a species with highly domed but lightly calcified colonies is likely to be just as prone to fragmentation, if not more, than a species that produces discoidal colonies.

Moreover, compared to species that produce flat colonies, we found that species with highly domed colonies are much less likely to be able to regenerate following fragmentation. This may suggest that colony shape is of importance for the life histories of cupuladriid species, as it is for other colonial filter feeders, particularly for feeding (see McKinney \& Jackson 1989, Okamura et al. 2001). However, it may be more likely that colonies that 'deliberately' fragment will possess specific strategies to enhance regeneration, while colonies that fragment rarely may not be able to regenerate if they do fragment.

The cupuladriids of Central America show a great range of life history strategies that correlate with a similarly wide range of morphologies. Species that invest heavily in vegetative growth tend to invest less in colony protection and tend to produce wide flat colonies that physically fragment more often. This enables the 'vegetative' growth of the colony to act as a mode of propagation and consequently results in a population having a greater proportion of their colonies produced through asexual propagation.

Our results demonstrate that species that invest less in colony-margin growth tend to invest more heavily in colony protection by producing small, heavily calcified, more highly domed colonies that protect the colony from fragmentation. As a result, these species have a lower proportion of their colonies derived from asexual propagation. We suggest that increased colony protection in this way is an adaptive strategy to enable the full and safe development of larvae. However, in order to test this hypothesis directly it is necessary to gather data on the fecundity of different species, a protocol not possible in the cupuladriids without detailed observation of living colonies over time.

Acknowledgements. We would like to thank F. Rodriguez, J. Alvarez and the crew of the RV 'Urraca', who helped with the enormous process of collecting, sampling and sorting the material for this project. M. Dick and T. Smith provided ideas and discussion. E. Håkansson, B. Okamura and K. O'Dea gave extremely valuable comments on the manuscript as did 2 anonymous reviewers. Financial support was provided by a Smithsonian Postdoctoral fellowship to A.O., Scholarly Studies grants to J.B.C.J. and H.F., Walcott Studies Grant to J.B.C.J. and NSF grant EAR03-45471 to J.B.C.J.

\section{LITERATURE CITED}

Baluk W, Radwanski A (1977) The colony regeneration and life habitat of free-living bryozoans, Cupuladria canariensis (Busk) and C. haidingeri (Reuss) from the Korytnica Clays (Middle Miocene): Holy Cross Mountains, Poland. Acta Geol Pol 27(2):143-156

Boller ML, Swain TD, Lasker HR (2002) Skeletal morphology and material properties of a fragmenting gorgonian coral. Mar Ecol Prog Ser 228:131-141

Budd AF (2000) Diversity and extinction in the Cenozoic history of Caribbean reefs. Coral Reefs 19:25-35

Cheetham AH, Jackson JBC (2000) Neogene history of Cheilostome Bryozoa in tropical America. Proc 11th Int Bryozool Assoc Conf: 1-16

Cheetham AH, Jackson JBC, Sanner J (2001) Evolutionary significance of sexual and asexual modes of propagation in Neogene species of the bryozoan Metrarabdotos in tropical America. J Paleontol 75:564-577

Chesher RH (1972) The status of knowledge of Panamanian echinoids, 1971, with comments on other echinoderms. Bull Biol Soc Wash 2:139-158

Coates AG, Obando JA (1996) The geological evolution of the Central American Isthmus. In: Jackson JBC, Budd AF, Coates AG (eds) Evolution and environment in tropical America. Chicago University, Chicago, IL, p 21-56

Coates AG, Aubry MP, Berggren WA, Collins LS, Kunk M (2003) Early Neogene history of the Central American arc from Bocas del Toro, western Panama. Geol Soc Am Bull 115:271-287

Collins LS (1996) Environmental changes in Caribbean shallow waters relative to the closing of the tropical American seaway. In: Jackson JBC, Budd AF, Coates AG (eds) Evolution and environment in tropical America. Chicago University, Chicago, IL, 130-167

Collins LS (1999) The Miocene to Recent diversity of Caribbean benthic foraminifera from the Central American Isthmus. Bull Am Paleontol 357:91-107

Colwell RK (1997) EstimateS: statistical estimation of species richness and shared species from samples. Version 5. 
User's guide and application published at: http://viceroy. eeb.uconn.edu/estimates

Cook PL (1965) Notes on the Cupuladriidae (Polyzoa, Anasca). Bull Br Mus (Nat Hist) Zool 13:151-187

Cook PL, Chimonides PJ (1978) Observations on living colonies of Selenaria (Bryozoa, Cheilostomata) I. Cah Biol Mar 19:147-158

Cook PL, Chimonides PJ (1983) A short history of the lunulite Bryozoa. Bull Ma Sci 33:566-581

Cook PL, Chimonides PJ (1994) Notes on the family Cupuladriidae (Bryozoa), and on Cupuladria remota sp. n. from the Marquesas Islands. Zool Scr 23:251-268

Dartevelle E (1932) Contribution a l'etude des Bryozoaires fossiles de l'Eocene de la Belgique, Ann Soc R Zool Belg LXIII:70-72, Pl. II, Figs. 35

D'Croz L, Robertson DR (1997) Coastal oceanographic conditions affecting coral reefs on both sides of the Isthmus of Panama. Proc 8th Int Coral Reef Symp 2:2053-2058

D'Croz L, Del Rosario JB, Gomez JA (1991) Upwelling and phytoplankton in the Bay of Panama. Rev Biol Trop 39: 233-241

Dick MH, Herrera Cubilla A, Jackson JBC (2003). Molecular phylogeny and phylogeography of free-living Bryozoa (Cupuladriidae) from both sides of the Isthmus of Panama. Mol Phylogenet Evol 27:355-371

Glynn PW (1982) Coral communities and their modifications relative to past and prospective Central American seaways. Adv Mar Biol 19:91-132

Gotelli NJ, Entsminger GL (2001) EcoSim: null models software for ecology. Version 7.0. Acquired Intelligence Inc. \& Kesey-Bear. http://homepages.together.net/ gentsmin/ ecosim.htm

Håkansson E (1973) Mode of growth of the Cupuladriidae (Bryozoa, Cheilostomata). In: Larwood GP (ed) Living and fossil Bryozoa. Academic Press, London, p 287-298

Håkansson E, Winston JE (1985) Interstitial bryozoans: unexpected life forms in a high energy environment. In: Nielsen C, Larwood GP (eds) Bryozoa: Ordovician to Recent. Olsen \& Olsen, Fredensborg, p 125-134

Håkansson E, Thomsen E (2001) Asexual propagation in cheilostome Bryozoa: evolutionary trends in a major group of colonial animals. In: Jackson JBC, Lidgard S, McKinney FK (eds) Evolutionary patterns: growth, form and tempo in the fossil record. University of Chicago Press, Chicago, IL, p 326-347

Harper JL (1977) Population biology of plants. Academic Press, London

Harrison PL, Wallace CC (1990) Coral reproduction. In: Dubinsky Z (ed) Ecosystems of the world: coral reefs. Elsevier Science Publishers BV, Amsterdam, p 133-208

Highsmith RC (1982) Reproduction by fragmentation in corals. Mar Ecol Prog Ser 7:207-226

Hoffman RJ (1986) Variation in contributions of asexual reproduction to the genetic structure of populations of the sea anemone Metridium senile. Evolution 40:357-365

Hughes RN, JM Cancino (1985) An ecological overview of cloning in metazoa. In: Jackson JBC, Buss LW, Cook RE (eds) Population biology and evolution of clonal organisms. Yale University Press, New Haven, NJ, p 153-186

Hughes TP, Jackson JBC (1980) Do corals lie about their age? Some demographic consequences of partial mortality, fission, and fusion. Science 209:713-715

Jackson JBC (1979) Morphological strategies of sessile animals. In: Larwood G, Rosen BR (eds) Biology and systematics of colonial organisms. Academic Press, London, p 499-555

Jackson JBC (1985) Distribution and ecology of clonal and aclonal benthic invertebrates. In: Jackson JBC, Buss LW, Cook RE (eds) Population biology and evolution of clonal organisms. Yale University Press, New Haven, NJ, p 297-355

Jackson JBC (1986) Modes of dispersal of clonal benthic invertebrates: consequences for species' distributions and genetic structure of local populations. Bull Mar Sci 39: 588-606

Jackson JBC, Coates AG (1986) Life cycles and evolution of clonal (modular) animals. Phil Trans R Soc 313:7-22

Jackson JBC, D'Croz L (1997) The ocean divided. In: Coates AG (ed) Central America: a natural and cultural history. Yale University Press, New Haven, CT, p 38-71

Jackson JBC, Herrera Cubilla A (2000) Adaptation and constraint as determinants of zooid and ovicell size among encrusting ascophoran cheilostone bryozoa from opposite sides of the Isthmus of Panama. In: Herrera Cubilla A, Jackson JBC (eds) Proc Int Bryozoology Association Conference, 2000. Smithonian Tropical Research Institute, Balboa, p 249-258

Jackson JBC, Hughes TP (1985) Adaptive strategies of coralreef invertebrates. Am Sci 73:265-274

Jackson JBC, Jung P, Fortunato H (1996) Paciphillia revisited: transisthmian evolution of the Strombina Group (Gastropoda: Columbellidae). In: Jackson JBC, Budd AF, Coates AG (eds) Evolution and environment in tropical America. University of Chicago Press, Chicago, IL, p 234-270

Jebram D (1977) Experimental techniques and culture methods. In: Woolacott RM, Zimmer RL (eds) Biology of Bryozoans. Academic Press, New York, p 273-306

Jones DF, Hasson PF (1985) History and development of the marine invertebrate faunas separated by the central American isthmus. In: Stehli FG, Webb SD (eds) The great American biotic interchange. Plenum Press, New York, p 325-355

Kovach WL (1998) MVSP — a multivariate statistical package for Windows, Ver 3.0. Kovach Computing Services, Pentraeth

Lagaaij R (1963) Cupuladria canariensis (Busk) - portrait of a bryozoan. Palaeontology 6:172-217

Lasker HR (1984) Asexual reproduction, fragmentation, and skeletal morphology of a plexaurid gorgonian. Mar Ecol Prog Ser 19:261-268

Lasker HR (1990) Clonal propagation and population dynamics of a gorgonian coral. Ecology 71:1578-1589

Lee DJ, Noble JPA (1990) Reproduction and life strategies in the Paleozoic tabulate coral Paleofavosites capax (Billings). Lethaia 23(3):257-272

Lessios H (1990) Adaptation and phylogeny as determinants of egg size in echinoderms from the two sides of the Isthmus of Panama. Am Nat 135:1-13

Lewis WM (1987) The cost of sex. In: Stearns SC (ed) The evolution of sex and its consequences. Birkhäuser Verlag, Basel

Lewis JB (1991) Testing the coral fragment size-dependent survivorship hypothesis in calcareous hydrozoan Millepora complanata. Mar Ecol Prog Ser 70:101-104

Marcus E, Marcus E (1962) On some lunulitiform Bryozoa. Univ São Paulo Bol Faculd Phil Sci Let Zool 3:111-353

McKinney FK (1983) Asexual colony multiplication by fragmentation: an important mode of genet longevity in the Carboniferous bryozoan Archimedes. Paleobiology 9:35-43

McKinney FK, Jackson JBC (1989) Bryozoan evolution. Unwin Hyman, Boston, MA

O'Dea A, Jackson JBC (2002) Bryozoan growth mirrors contrasting seasonal regimes across the Isthmus of Panama. Palaeogeogr Palaeoclimatol Palaeoecol 185:77-94 
O'Dea A, Okamura B (1999) Influence of seasonal variation in temperature, salinity, and food availability on module size and colony growth in the estuarine bryozoan Conopeum seurati. Mar Biol 135:581-588

Okamura B, Harmelin JG, Jackson JBC (2001) Refuges revisited: enemies versus flow and feeding as determinants of sessile animal distribution and form. In: Jackson JBC, Lidgard S, McKinney FK (eds) Evolutionary patterns: growth, form and tempo in the fossil record. University of Chicago Press, Chicago, IL, p 61-93

Roy K, Jablonski D, Valentine JW (2000) Dissecting latitudinal diversity gradients: functional groups and clades of marine bivalves. Proc R Soc Lond 267:293-299

Smith LD, Hughes TP (1999) An experimental assessment of survival, re-attachment and fecundity of coral fragments. J Exp Mar Biol Ecol 235:147-165

Soest RWM van (1994) Demosponge distribution patterns. In: Soest RWM van, Kempen TMG, van Braekman JC (eds) Sponges in space and time. Biology, Chemistry, Paleontology. Proc 4th Int Porifera Congress, Amsterdam, 19-23 April 1993. A.A. Balkema, Rotterdam, p 213-223

Teranes JL, Geary DH, Bemis BE (1996) The oxygen isotopic

Editorial responsibility: Roger Hughes (Contributing Editor), Bangor, UK record of seasonality in Neogene bivalves from the Central American isthmus. In: Jackson JBC, Budd AF, Coates AG (eds) Evolution and environment in tropical America. Chicago University, Chicago, IL, p 105-129

Thomsen E, Håkansson E (1995) Sexual versus asexual dispersal in clonal animals-examples from cheilostome bryozoans. Paleobiology 21(4):496-508

Thompson GG, Withers PC (2003) Effect of species richness and relative abundance on the shape of the species accumulation curve. Aust Ecol 28(4):355

Tunnicliffe V (1981) Breakage and propagation of the stony coral Acropora cervicornis. Proc Natl Acad Sci 78: 2427-2431

Vermeij GJ (1978) Biogeography and adaptation: patterns of marine life. Harvard University Press, Cambridge, MA

Winston JE (1976) Experimental culture of the estuarine ectoproct Conopeum tennuissiumum from Chesapeake Bay. Biol Bull (Woods Hole) 150:318-335

Winston JE (1988) Life histories of free-living bryozoans. Natl Geogr Res 4:528-539

Wulff JL (1991) Asexual fragmentation, genotype success, and population dynamics of erect branching sponges. J Exp Mar Biol Ecol 149:227-247

Submitted: February 6, 2004; Accepted: August 24, 2004 Proofs received from author(s): September 21, 2004 